The Economic Journal, 110 (April), 484-508. (C) Royal Economic Society 2000. Published by Blackwell Publishers, 108 Cowley Road, Oxford OX4 1JF, UK and 350 Main Street, Malden, MA 02148, USA.

\title{
STRATEGIC TRADE AND INDUSTRIAL POLICY TOWARDS DYNAMIC OLIGOPOLIES*
}

\author{
J. Peter Neary and Dermot Leahy
}

\begin{abstract}
We characterise optimal trade and industrial policy in dynamic oligopolistic markets. If governments can commit to future policies, optimal first-period intervention should diverge from the profit-shifting benchmark to an extent which exactly offsets the strategic behaviour implied by Fudenberg and Tirole's 'animal spirits' taxonomy of business strategies. Without government commitment, there is an additional basis for intervention, whose sign depends on the strategic substitutability between future policy and current actions. We consider a variety of applications (to R\&D spillovers, consumer switching costs, etc.) and also extensions to constrained second-best policies.
\end{abstract}

The theory of strategic trade policy has grown from precocious urchin to mature teenager and is now part of the central canon of international trade theory. Much of its initial appeal came from the fact that it appeared to provide a stronger justification for interventionist measures such as tariffs and export subsidies than traditional competitive theory. However, as is now well known, the specific policy recommendations of the theory are highly sensitive to changes in assumptions about firm behaviour, entry, and so on. For this reason, possibly a more important contribution of the theory is that it highlights a key aspect of public policy in oligopolistic markets: that governments and firms are likely to differ in their ability to commit to future actions. Thus the desirability of intervention, whether an export subsidy as in Brander and Spencer (1985) or an export tax as in Eaton and Grossman (1986), derives from the government's assumed ability to commit to policies which will remain in force while firms take their decisions on outputs or prices. The optimal policy moves the home firm to the point which it would attain unaided if it had a Stackelberg first-mover advantage.

Yet the superior ability of governments to commit is questionable on two counts. First, firms too may have the ability to commit to variables such as capacity, advertising or R\&D, which will affect the strategic environment in which policies are set and outputs and prices are chosen in the future. Second, a government's assessment of its own powers of commitment may not be shared by the private sector. With or without a past history of reneging on its commitments, its policy announcements may lack credibility with the firms

\footnotetext{
* For helpful comments we are grateful to Elhanan Helpman, Kai-Uwe Kühn, Thierry Mayer, Massimo Motta, Konrad Stahl, Xavier Vives and participants in seminars at Aarhus, Barcelona (UAB), Basel, Cardiff, Dundee, Essex, Hong Kong (CUHK), Konstanz, Mannheim and Trinity College Dublin; at the CEPR-CUSO Conference on Trade, Location and Technology, Champéry, February 1996; at the 1996 Annual Conference of the Irish Economic Association; at EEA 96 in Istanbul; and at the CEPR Workshop on Competition and Trade Policy, Barcelona, December 1997. This research forms part of the International Economic Performance programme of the Centre for Economic Performance at the London School of Economics, funded by the UK ESRC, and was undertaken with support from the European Union Phare ACE Programme 1996, contract no. P96-6092-R. An earlier version was circulated as CEPR Discussion Paper No. 1968.
} 
whose behaviour it is trying to influence. Of course, it may also be the case that the government does not in fact possess the ability to commit to policies some time in the future. These considerations prompt a search for policies which are time consistent.

The purpose of this paper is to consider the implications for strategic trade and industrial policy of allowing firms to make commitments in advance. We do not rule out government commitment altogether: to do so would be unrealistic and would remove any basis for strategic policy. However, we allow for the possibility that governments may be unable to commit far into the future; and also for the possibility that firms may be able to take some decisions (such as investment, R\&D, etc.) which have effects over a longer time horizon than that over which the government can commit.

As we shall see, models of dynamic oligopolies with imperfect government commitment introduce two new motives for government intervention in addition to the standard profit-shifting motive familiar from static models. First, in the manner first studied by Spence (1977) and Dixit (1980), firms have an incentive to engage in behaviour which will improve their strategic position vis-à-vis their rivals in the future. This type of strategic behaviour is socially wasteful (even when the rival firm is foreign) and government policy should be addressed towards offsetting it. Second, if the government cannot commit to future policies, firms have an additional incentive to try and influence their future entitlement to assistance, for example, by over-investing in order to qualify for a higher subsidy. The need to restrain the home firm from this strategic behaviour provides the government with an additional motive for intervention in the earlier period.

Aspects of imperfect commitment and dynamic behaviour in models of strategic policy have been explored in a number of recent papers. Brander and Spencer (1987) consider a model where an incumbent home firm chooses its level of R\&D before the government chooses its output subsidy. Carmichael (1987), followed by Gruenspecht (1988) and Neary (1991), explores the implications of allowing firms to set prices before the government chooses its subsidy. Maskin and Newbery (1990) consider the optimal time-consistent import tariff on a natural resource produced by a competitive industry. Goldberg (1995) and Maggi (1996) consider optimal policy in models where firms choose their capacities before the output or price stage. Finally, we have explored some of these issues in models with learning by doing (Leahy and Neary, 1994; 1999b) and R\&D (Leahy and Neary, 1996; 1997). However, this literature is fragmented and the general lessons are often obscured by the particularities of individual models. In this paper we present a general framework which nests most of these models and relates them to the taxonomy of business strategies developed by Fudenberg and Tirole (1984). ${ }^{1}$ Our general approach identifies common themes in a disparate literature and extends existing models in significant new directions.

\footnotetext{
1 Laussel and Montet (1994) use the Fudenberg and Tirole taxonomy in a different manner to interpret the results of strategic trade policy in one-period models.

(C) Royal Economic Society 2000
} 
In the remainder of the paper we address the questions raised here by first considering a general dynamic two-firm multi-period model in Section 1. The model adopts the standard 'third-market' framework of Brander and Spencer (1985), abstracting from domestic consumption in order to focus on the strategic interaction between firms and government. ${ }^{2}$ Rules for optimal intervention are derived under different assumptions about the ability of firms and government to commit to future actions. These rules are then applied to a series of special models in Section 2. This allows us to consider the implications for policy of alternative assumptions about the dynamic links between markets. Finally, Section 3 returns to the general two-period model and shows how it may be extended to deal with second-best problems, where the government can intervene in only one period.

\section{Optimal Intervention in a General Model of Dynamic Oligopoly}

\subsection{The Firm's Decision Problem}

We consider a market with two firms, denoted 'home' and 'foreign', which compete over an indefinite (though finite) number $T$ of time periods. In each period $t$, each firm takes an action, choosing the value of some variable, $a_{t}$ for the home firm and $b_{t}$ for the foreign firm. This specification allows for many alternative types of oligopolistic interaction: in each period the decision variables might be output, price, $\mathrm{R} \& \mathrm{D}$, etc. Each firm seeks to maximise the present value of its profits, so the decision problem of the home firm can be written as:

$$
\underset{\mathbf{a}}{\operatorname{Max}} \pi(\mathbf{a}, \mathbf{b}, \mathbf{s})=R(\mathbf{a}, \mathbf{b})+S(\mathbf{a}, \mathbf{b}, \mathbf{s}),
$$

where $\mathbf{a}$ and $\mathbf{b}$ are the vectors of the home and foreign firm's actions respectively. Here $\pi$ denotes the present value of the firm's profits, equal to the sum of the present values of its gross profits (i.e., sales revenue less total costs) $R$ and its subsidy income $S$. Each of these components is a twice differentiable function of its own and its rival's actions; in addition, $S$ depends on a vector of subsidy rates chosen by the home government, s. In many applications, the subsidy is directly related to the firm's decision variable, so $S^{t}=s_{t} a_{t}$ and $S_{a t}^{t} \equiv \partial S^{t} / \partial a_{t}=s_{t}$, where $S^{t}$ is subsidy income in period $t$. An exception is the case of an output subsidy in Bertrand competition, where the derivative of $S^{t}$ with respect to $a_{t}$ has the opposite sign to $s_{t} \cdot{ }^{3}$ As for the foreign firm, its

2 One rationale for this is that all output is exported. Alternatively, we can assume that some output is domestically consumed, that home and foreign markets are integrated and that domestic consumer surplus does not enter the social welfare function.

3 In Bertrand competition, the firm's decision variable $a_{t}$ is its price, but its subsidy income $S^{t}$ equals $s_{t} q_{t}$, where $q_{t}$ is the period- $t$ demand function which in general depends on all current and past actions (prices). Hence, $S_{a t}^{t}=s_{t} \partial q_{t} / \partial a_{t}$, which has the opposite sign to $a_{t}$. A simpler approach, following Brander (1995), is to assume that the subsidy is always directly related to the firm's decision variable, so when this variable is its price, a subsidy to it is equivalent to an output tax. However, this equivalence between price and output subsidies does not extend to the case of Sequence Equilibrium discussed below.

(C) Royal Economic Society 2000 
decision problem is similar to (1) but with no subsidy terms; we assume that the foreign firm is not assisted by its government:

$$
\operatorname{Max}_{\mathbf{b}} \pi^{*}(\mathbf{b}, \mathbf{a}) \text {. }
$$

The basic results of the paper are most easily derived using the multi-period specification in (1). However, in order to interpret them and to apply them to many examples it is desirable to focus on a two-period special case. Assuming that firms compete over only two periods, labelled ' 1 ' and ' 2 ', allows us to write the home firm's profit function as follows (where $\rho$ denotes the discount factor):

$$
\pi(\mathbf{a}, \mathbf{b}, \mathbf{s})=\pi^{1}\left(a_{1}, b_{1}, s_{1}\right)+\rho \pi^{2}\left(a_{1}, b_{1}, a_{2}, b_{2}, s_{2}\right) .
$$

(Similarly for the gross profit and subsidy income functions: $R=R^{1}+\rho R^{2}$ and $S=S^{1}+\rho S^{2}$.) This specification draws attention to the dynamics of the model. While first-period profits depend only on variables in that period, second-period profits are directly affected by the actions taken in the previous period. The influence of the firm's own action $a_{1}$ arises from dynamic linkages such as investment in capacity or learning by doing; the influence of the foreign firm's action $b_{1}$ reflects an externality such as R\&D spillovers.

\subsection{Firm Behaviour under Alternative Assumptions about Commitment}

The second respect in which the model is dynamic is in its assumptions about commitment. As in our earlier work (Leahy and Neary, 1997, 1999b), this has a number of aspects. We assume throughout that the government is able to commit intra-temporally in all periods, setting each subsidy $s_{t}$ before the firms choose their actions in the same period $a_{t}$ and $b_{t}$. However, it may or may not be able to commit inter-temporally, setting the subsidy $s_{t}$ before the firms choose their actions in earlier periods $a_{t-i}$ and $b_{t-i}$. This leaves a number of alternative assumptions about move order and we concentrate on three central cases (which are the only ones that can arise in the two-period model). In two of these cases the government can commit in period 1 to all future subsidies. Subject to this, we refer to the case where firms can commit in period 1 to all their future actions as 'Full Commitment Equilibrium' or 'FCE'; and to the case where firms cannot commit to any future actions as 'Government-Only Commitment Equilibrium' or 'GCE'. Finally, we refer to the case where no agents can commit in advance, and in particular where the government cannot commit in advance to any future subsidies, as 'Sequence Equilibrium' or 'SE'. For each of our three sets of assumptions about commitment the solution concept is that of Nash subgame perfect equilibrium. The values of all variables will differ in general between the three equilibria, although it is convenient to derive the first-order conditions in a general form which applies in all three cases. Finally, we ignore issues of exit and entry and assume that a unique interior equilibrium exists in each case.

The implications of the different assumptions about commitment can be

(C) Royal Economic Society 2000 
seen more concretely by considering the behaviour of the home firm, which chooses the value of $a$ to set its marginal profitability to zero. In general this implies the following:

$$
\left(\frac{d \pi}{d \mathbf{a}}\right)^{\prime}=\boldsymbol{\pi}_{\mathbf{a}}^{\prime}+\boldsymbol{\pi}_{\mathbf{b}}^{\prime} \frac{d \mathbf{b}}{d \mathbf{a}}+\boldsymbol{\pi}_{\mathbf{s}}^{\prime} \frac{d \mathbf{s}}{d \mathbf{a}}=\mathbf{0} .
$$

Here a prime denotes the transpose of a vector, so (4) represents $T$ first-order conditions, one for each period; and subscripts to functions denote partial derivatives. The expressions $d \mathbf{b} / d \mathbf{a}$ and $d \mathbf{s} / d \mathbf{a}$ in (4) reflect the home firm's ability, if any, to affect the foreign firm's actions and the subsidy levels, respectively. Each of the three terms in (4) arises in SE, but only the first two arise in GCE and only the first in FCE. The precise form which these terms take is the focus of the remainder of Section 1.

\subsection{Welfare and Optimal Subsidies}

This completes our discussion of the home firm. Turning to the government we assume that all output is exported and that the marginal social cost of funds is unity. Hence welfare equals the firm's profits net of subsidy payments:

$$
W(\mathbf{a}, \mathbf{b})=\pi(\mathbf{a}, \mathbf{b}, \mathbf{s})-S(\mathbf{a}, \mathbf{b}, \mathbf{s})=R(\mathbf{a}, \mathbf{b}) .
$$

This welfare function depends on both home and foreign decision variables (though not directly on the subsidies) and we wish to find the values of the subsidies which will maximise it. To solve this problem with two targets (a and b) and one instrument (s), it is useful to think of the government's choice of subsidies as giving it direct control over the home firm's actions a, while it controls the foreign firm's actions indirectly. Of course, the ways in which this control is exercised, and so the details of how (5) is maximised, depend on the government's powers of commitment. Nevertheless, it is insightful to begin with a general formulation which covers all cases.

Totally differentiating (5) gives a necessary condition for welfare maximisation:

$$
d W=\mathbf{R}_{\mathbf{a}}^{\prime} d \mathbf{a}+\mathbf{R}_{\mathbf{b}}^{\prime} d \mathbf{b}=0 .
$$

To solve for the optimal subsidies we first replace the coefficient of $d \mathbf{a}$ using the home firm's first-order condition (4) (exploiting the fact that $\pi_{\mathbf{a}}=$ $\mathbf{R}_{\mathbf{a}}+\mathbf{S}_{\mathbf{a}}$ ). As for the second term, it can be eliminated by using the foreign firm's first-order conditions: ${ }^{4}$

$$
\left(\frac{d \pi^{*}}{d \mathbf{b}}\right)^{\prime}=\left(\boldsymbol{\pi}_{\mathbf{b}}^{*}\right)^{\prime}+\left(\boldsymbol{\pi}_{\mathbf{a}}^{*}\right)^{\prime} \frac{d \mathbf{a}}{d \mathbf{b}}=\mathbf{0} .
$$

The government solves these equations for generalised reaction functions,

${ }^{4}$ In SE the foreign firm also anticipates the effects of its actions on the home government's future subsidy. However, this only affects its profits through the home firm's future actions, so there is no $d \mathbf{s} / d \mathbf{b}$ term in (7).

(C) Royal Economic Society 2000 
which express the foreign firm's actions as functions of all of the home firm's: $\mathbf{b}=\mathbf{B}(\mathbf{a})$. In differential form:

$$
d \mathbf{b}=\mathbf{B}_{\mathbf{a}} d \mathbf{a} .
$$

Crucial to the results is that the matrix $\mathbf{B}_{\mathbf{a}}$ gives the derivatives of foreign actions with respect to home actions from the perspective of the home government, which differ in general from the matrix $d \mathbf{b} / d \mathbf{a}$ in (4) which are from the perspective of the home firm. The difference between the two reflects the government's superior (intratemporal) commitment power.

We can now use the differentiated reaction functions (8) to eliminate $d \mathbf{b}$ from (6), and solve for the optimal subsidies:

$$
\mathbf{S}_{\mathbf{a}}^{\prime}=\mathbf{R}_{\mathbf{b}}^{\prime} \mathbf{B}_{\mathbf{a}}-\boldsymbol{\pi}_{\mathbf{b}}^{\prime} \frac{d \mathbf{b}}{d \mathbf{a}}-\boldsymbol{\pi}_{\mathbf{s}}^{\prime} \frac{d \mathbf{s}}{d \mathbf{a}} .
$$

This equation is the central result of the paper. For some purposes it is helpful to write it in full for the two-period case. This gives:

$$
\begin{gathered}
S_{a_{1}}^{1}=-\rho S_{a_{1}}^{2}+\left(R_{b_{1}}^{1}+\rho R_{b_{1}}^{2}\right) B_{11}+\rho R_{b_{2}}^{2} B_{21}-\pi_{b_{2}} \frac{d b_{2}}{d a_{1}}-\pi_{s_{2}} \frac{d s_{2}}{d a_{1}}, \\
S_{a_{2}}^{2}=\rho^{-1}\left(R_{b_{1}}^{1}+\rho R_{b_{1}}^{2}\right) B_{12}+R_{b_{2}}^{2} B_{22} .
\end{gathered}
$$

Recall that $S_{a t}^{t}$ is the partial derivative of the subsidy revenue function $S^{t}$ with respect to $a_{t}$; in most cases it is simply $s_{t}$, except in the case of an output subsidy in Bertrand competition when it equals $s_{t} \partial q_{t} / \partial a_{t}$ and so is inversely related to the subsidy. As for the cross-term $S_{a 1}^{2}$ in (10), it represents the direct or non-strategic effect of a change in $a_{1}$ on future subsidy revenue. ${ }^{5}$ In most cases this term is zero; an exception is the case of an output subsidy in Bertrand competition when it equals $s_{2} \partial q_{2} / \partial a_{1}$ and so reflects intertemporal effects such as switching costs in demand, discussed in Section 2.5 below. When the term is non-zero the two equations have to be solved recursively, with the optimal value of $s_{2}$ first calculated from (11) and then substituted into (10) to calculate the optimal value of $s_{1}$.

\subsection{Optimal Policy with Full Commitment}

Consider first the FCE case where both government and firms (in that order) commit in period 1 to their actions in all periods. As already noted, the final two terms in (9) (and hence in (10)) do not arise in FCE. Hence, irrespective of the number of periods, the expression for the optimal subsidies takes a particularly simple form:

$$
\mathbf{S}_{\mathbf{a}}^{\prime}=\mathbf{R}_{\mathbf{b}}^{\prime} \mathbf{B}_{\mathbf{a}} \text {. }
$$

Both the form of this equation and the rationale for intervention which it provides are identical to those in one-period models. Algebraically, (12) states

\footnotetext{
5 Following Fudenberg and Tirole (1984), we call the first term in (4) the 'direct' or 'non-strategic' effect of the firm's actions. Of course, the firm is always a Nash player, so strategic considerations arise even for this term; however, the label 'non-strategic' is convenient and hopefully unambiguous. 
that the optimal subsidy (or, in Bertrand competition, the optimal subsidy times the slope of the demand function) should equal the cross-effect of foreign actions on home revenue $\left(\mathbf{R}_{\mathbf{b}}\right)$ times the slope of the foreign reaction function $\left(\mathbf{B}_{\mathbf{a}}\right)$. (With many periods all of these terms should be interpreted as vectors or matrices where appropriate.) In terms of economic intuition, the justification for intervention is that, because of its superior commitment power, the government is able to move the foreign firm along its reaction function to the Stackelberg equilibrium, something which the home firm itself cannot credibly do. We will follow standard practice and refer to this as the 'profit-shifting' motive for intervention.

Of course, the simplicity of (12) arises from the compact matrix notation. When we consider the elements in this expression period by period, matters appear more complex, as (10) and (11) show. (We consider here only the pure profit-shifting effects, represented by terms involving the $B_{i j}$ derivatives. All other terms are discussed elsewhere.) To interpret these terms, we introduce the distinction between inter- and intra-temporal profit shifting. In each equation there is one term, $R_{b t}^{t} B_{t t}(t=1,2)$, all of whose components relate exclusively to the same period. These terms represent the standard intratemporal profitshifting motive: if there are no links between periods all other terms vanish (since $R_{b j}^{i}=B_{i j}=0$ for $i \neq j$ ) and both equations collapse to $S_{a t}^{t}=R_{b t}^{t} B_{t t}$ $(t=1,2)$. This yields the familiar results of static strategic trade policy. ${ }^{6}$ In addition, because of the dynamic structure of the model, there is an intertemporal profit-shifting motive in both periods, represented by cross-terms such as $R_{b 1}^{2}$ and $B_{12}$ in (10) and (11). Calculating all the components of $\mathbf{S}_{\mathbf{a}}$ in any particular application is likely to be difficult. However, the difficulty is no more and no less than that needed to sign any matrix comparative statics expression. ${ }^{7}$ Summarising the results so far:

Proposition 1. In FCE, the formula for the optimal subsidies is a matrix generalisation of the static profit-shifting formula, reflecting inter- as well as intra-temporal rentshifting.

\subsection{Optimal Policy with Strategic Competition by Firms}

Consider next the GCE case, when the government can still commit in advance to future subsidies but firms cannot commit in advance to future actions and

\footnotetext{
${ }^{6}$ When competition is Cournot: $S_{a t}^{t}$ equals $s_{t}$; $R_{b t}^{t}$ is negative provided goods are Antonelli substitutes in demand; and $B_{t t}$ is negative provided outputs are strategic substitutes. Hence an export subsidy is optimal, as in Brander and Spencer (1985). By contrast, when competition is Bertrand: $S_{a t}^{t}$ equals $s_{t} \partial q_{t} / \partial a_{t} ; R_{b t}^{t}$ is positive provided goods are Hicksian substitutes in demand; and $B_{t t}$ is positive provided prices are strategic complements. Hence an export tax is optimal, as in Eaton and Grossman (1986).

7 To see this, we calculate $\mathbf{B}_{\mathbf{a}}$ explicitly, using the first-order conditions for the foreign firm (i.e., (7) specialised to the FCE case): $\boldsymbol{\pi}_{\mathbf{b}}^{*}(\mathbf{b}, \mathbf{a})=0$. Totally differentiating and substituting in (12) gives: $\mathbf{S}_{\mathbf{a}}^{\prime}=-\mathbf{R}_{\mathbf{b}}^{\prime}\left(\boldsymbol{\pi}_{\mathbf{b b}}^{*}\right)^{-1} \boldsymbol{\pi}_{\mathbf{b a}}^{*}$. (Compare, for example, the single-period Cournot result given by Brander (1995), equation (3.17).) The only general restriction on this formula is that $\boldsymbol{\pi}_{\mathbf{b b}}^{*}$ must be negative definite from the foreign firm's second-order condition. However, other restrictions may be imposed under appropriate additional assumptions. For example, if in every period the foreign firm's action is a strategic substitute for every action of the home firm, then all the elements of $\boldsymbol{\pi}_{\mathbf{b a}}^{*}$ are negative.
}

(C) Royal Economic Society 2000 
so engage in strategic behaviour against each other. The home firm's strategic behaviour is represented by the second term in its first-order condition (4). As the second term in (9) shows, optimal policy requires that this strategic effect should be exactly offset.

One case where this has dramatic implications is where the home firm and the home government have the same ability to commit (both inter- and intratemporally) and so the same ability to manipulate the foreign firm. In that case, $\mathbf{B}_{\mathbf{a}}=d \mathbf{b} / d \mathbf{a}$, and (9) shows that the optimal subsidy is zero. ${ }^{8}$ This confirms from a different perspective the points made in the last sub-section. If the home firm can commit to the same extent as the home government, then it acts as a Stackelberg leader on its own, and the rationale for strategic trade policy disappears. By contrast, we concentrate on the case where $\mathbf{B}_{\mathbf{a}}$ and $d \mathbf{b} / d \mathbf{a}$ are different: the home firm is always a Nash player against the foreign firm, so all elements on and above the principal diagonal of the matrix $d \mathbf{b} / d \mathbf{a}$ are zero; whereas the home government always has superior commitment power (at least intratemporally), so some or all of the corresponding elements in the matrix $\mathbf{B}_{\mathbf{a}}$ are non-zero.

To obtain concrete results we must now specialise to the two-period case, where the key term is that involving $d b_{2} / d a_{1}$ in (10). This term has been extensively studied, most comprehensively by Fudenberg and Tirole (1984), and we follow their taxonomy here. ${ }^{9}$ The expression $d b_{2} / d a_{1}$ is the foreign firm's period- 2 response to a change in $a_{1}$, as anticipated by the home firm. It arises from the solution of the two second-period first-order conditions. That for the foreign firm implies a period-2 reaction function, $b_{2}=\psi\left(a_{1}, b_{1}, a_{2}\right)$. Differentiating this, the full response of $b_{2}$ to $a_{1}$ may be decomposed as follows:

$$
\frac{d b_{2}}{d a_{1}}=\psi_{a_{1}}+\psi_{a_{2}} \frac{d a_{2}}{d a_{1}},
$$

where the derivative $d a_{2} / d a_{1}$ arises from the joint solution of both firms' period-2 first-order conditions. The partial derivative $\psi_{a 1}$ in (13) reflects an intertemporal externality between the two firms. Otherwise the right-hand side is as in Fudenberg and Tirole and its contribution to profits may be broken into two components. First is the slope of the foreign firm's reaction function in the second period, $\psi_{a 2}$ : this is negative when second-period actions are strategic substitutes, and positive otherwise. Second is whether or not 'investment', in the sense of an increase in $a_{1}$, makes the home firm 'tough', in the sense of reducing the foreign firm's period- 2 profits. ${ }^{10}$ The resulting taxonomy, which is illustrated in Table 1, is now well-known, although we shall see in

\footnotetext{
${ }^{8}$ To be precise, when $\mathbf{B}_{\mathbf{a}}=d \mathbf{b} / d \mathbf{a}$, the expression for the optimal subsidy reduces to $\mathbf{S}_{\mathbf{a}}^{\prime}=-\mathbf{S}_{\mathbf{b}}^{\prime} \mathbf{B}_{\mathbf{a}}$. This implies zero optimal subsidies in all cases.

${ }^{9}$ Since there are two incumbent firms, the Fudenberg-Tirole taxonomy we follow is that for entry accommodation rather than entry deterrence.

${ }^{10}$ Ignoring $\partial \pi^{*} / \partial a_{1}$, the direct effect (if any) of $a_{1}$ on $\pi^{*}$, the effect of $a_{1}$ on the foreign firm's profits is: $d \pi^{*} / d a_{1}=\pi_{a 2}^{*}\left(d a_{2} / d a_{1}\right)$. By analogy with Fudenberg and Tirole, we assume (plausibly) that the cross-effects on profits in the second period, $\pi_{b 2}$ and $\pi_{a 2}^{*}$, have the same sign.
}

(C) Royal Economic Society 2000 
Table 1

Taxonomy of Strategic Effects and their Implications for Optimal Policy

\begin{tabular}{|c|c|c|}
\hline \multirow{2}{*}{$\begin{array}{l}\text { Slope of reaction } \\
\text { functions in period 2: }\end{array}$} & \multicolumn{2}{|c|}{ Investment makes the home firm: } \\
\hline & Tough: $\pi_{a_{2}}^{*} \frac{d a_{2}}{d a_{1}}<0$ & Soft: $\pi_{a_{2}}^{*} \frac{d a_{2}}{d a_{1}}>0$ \\
\hline & 'Top dog': 'Restrain' & 'Lean and hungry': 'Fatten' \\
\hline \multirow[t]{2}{*}{$\begin{array}{l}\text { Strategic substitutes } \\
\psi_{a_{2}}<1\end{array}$} & $\begin{array}{l}\mathrm{R} \& \mathrm{D}+\mathrm{C}: \operatorname{tax} a_{1} \\
\mathrm{LBD}+\mathrm{C}: \operatorname{tax} a_{1}\end{array}$ & $\mathrm{NR}+\mathrm{C}:$ subsidise $a_{1}$ \\
\hline & 'Puppy dog': 'Encourage' & 'Fat cat': 'Exercise' \\
\hline $\begin{array}{l}\text { Strategic complements } \\
\psi_{a_{2}}>1\end{array}$ & $\begin{array}{l}\mathrm{R} \& \mathrm{D}+\mathrm{B}: \text { subsidise } a_{1} \\
\mathrm{NR}+\mathrm{B}: \operatorname{tax} q_{1}\end{array}$ & LBD + B: subsidise $q_{1}$ \\
\hline
\end{tabular}

C: Cournot (output) competition; B: Bertrand (price) competition; R\&D: Research and development; LBD: Learning by doing; NR: Natural resources.

the next section that its detailed implications for policy are not immediately obvious.

For the present, note that the second term in (10) for the optimal period-1 subsidy exactly offsets the Fudenberg-Tirole strategic effect in the home firm's first-order condition (4). Heuristically, strategic behaviour by the home firm consumes real resources. Since the marginal social cost of funds is unity, it is more efficient for the government to restrain the home firm from this wasteful strategic behaviour while simultaneously shifting rents optimally just as in FCE. Summarising:

Proposition 2. In GCE, the formula for the optimal period-1 subsidy contains an additional term, which exactly offsets the Fudenberg and Tirole strategic effect.

Naturally, Fudenberg and Tirole's 'animal spirits' taxonomy of business strategies suggests an 'animal training' taxonomy of optimal policy responses. We explore this in more detail when we consider applications in the next section.

\subsection{Optimal Policy without Government Commitment}

Finally, consider the Sequence Equilibrium case, where the home government cannot commit in advance to its future subsidies and so the home firm has an incentive to play strategically against it, represented by the new third term in (4). The government in turn adjusts its optimal subsidy to offset this term, as the third term in (9) shows. The other terms in (10) and (11) also continue to apply in SE, but because all agents' actions are now sequential, the interpretation of the $B_{i j}$ coefficients is rather different.

To see how the subsidies are set in SE, consider the government's problem at the beginning of period 2. With $a_{1}$ and $b_{1}$ already determined, it faces a 
standard static problem and the optimal subsidy is given by the static rentshifting formula:

$$
S_{a_{2}}^{2}=R_{b_{2}}^{2} \psi_{a_{2}}
$$

This is a special case of (11), with $B_{12}$ equal to zero and $B_{22}$ equal to $\psi_{a 2}$, the slope of the foreign firm's period-2 reaction function. Of course, the terms in (14) depend on past decisions and so it can be solved for $s_{2}$ as a function of the period- 1 actions of both firms:

$$
s_{2}=s_{2}\left(a_{1}, b_{1}\right) .
$$

Both firms take this into account in choosing their first-period actions, which explains the $d \mathbf{s} / d \mathbf{a}$ term in (4). (In Section 2 and the Appendix we consider the sign of $d s_{2} / d a_{1}$ in detail.)

Finally, the government anticipates this behaviour in setting its period-1 subsidy, which explains the final term in (10). ${ }^{11}$ This term exactly offsets the home firm's strategic behaviour of varying $a_{1}$ in order to manipulate the period-2 subsidy. It is negative (since $\pi_{s 2}$ is positive) if and only if an increase in the home firm's period-1 action tends to raise the period-2 subsidy; i.e., if and only if $s_{2}$ is a strategic complement for $a_{1}$. Summarising:

Proposition 3. In SE, the formula for the optimal period-1 subsidy contains an additional term, which exactly offsets the strategic behaviour of the home firm vis-à-vis the home government, tending to lower $S_{a 1}^{1}$ if and only $d s_{2} / d a_{1}$ is positive; i.e., if and only if the period-2 subsidy is a strategic complement for the home firm's period-1 action.

\subsection{Welfare Comparisons between Equilibria}

So far, we have isolated the factors which determine the optimal subsidies, and in the next section we show that they can be signed in many applications. We would also like to give a welfare ranking of the different equilibria, but this is not possible in general. However, it is in one special case, where the foreign firm has no intertemporal links:

Proposition 4. If the foreign firm has no intertemporal links, the real equilibrium (including the level of welfare) is the same in all three cases. Only the subsidies differ.

This proposition is easily proved by substituting for the optimal subsidies (9) into the home firm's first-order conditions (4). This gives:

$$
\mathbf{R}_{\mathbf{a}}[\mathbf{a}, \mathbf{B}(\mathbf{a})]^{\prime}+\mathbf{R}_{\mathbf{b}}[\mathbf{a}, \mathbf{B}(\mathbf{a})]^{\prime} \mathbf{B}_{\mathbf{a}}(\mathbf{a})=\mathbf{0}
$$

which is the Stackelberg equilibrium condition in matrix form. A sufficient condition for this to be invariant to changes in the assumptions about move

\footnotetext{
11 Of course, the rent-shifting coefficients are also very different. For example, $B_{21}$ takes a relatively simple form since it can be calculated directly from the foreign firm's period-2 reaction function: $B_{21}=\psi_{a 1}+\psi_{b 1}\left(d b_{1} / d a_{1}\right)$. The externality term involving $\psi_{a 1}$ enters positively here and negatively in the expression for $d b_{2} / d a_{1}$ in (10). However, these are the only terms which cancel in general.

(C) Royal Economic Society 2000
} 
order is that the matrix $\mathbf{B}_{\mathbf{a}}$ is diagonal, in other words, that the foreign firm has no intertemporal links.

Intuitively, the key to this result is that with no intertemporal links, the foreign firm faces the same intertemporal incentives in all three games. Hence its reaction functions are the same and so the home government (which, as always, controls the actions of the home firm) implements the same optimal solution.

\section{Applications ${ }^{12}$}

Equation (9), and its two-period specialisation in (10) and (11), is the key result of the paper. In this section we consider its implications in some interesting special cases.

\subsection{Investment in Capacity or REDD}

The simplest type of intertemporal linkage to which our general approach may be applied is investment where all the benefits accrue to the firm which undertakes it. In this case, each firm's first-period decision variable is its level of investment, while its second-period decision variable is either output or price. The home firm's revenue functions simplify to:

$$
R^{1}\left(a_{1}\right)=-C^{1}\left(a_{1}\right), R^{2}\left(a_{1}, a_{2}, b_{2}\right)=\hat{R}^{2}\left(a_{2}, b_{2}\right)-C^{2}\left(a_{1}, q_{2}\right),
$$

where $\hat{R}^{2}\left(a_{2}, b_{2}\right)$ is sales revenue in period 2. This case is simpler because firms do not compete directly in period 1, and so the home firm's revenue functions do not depend directly on the foreign firm's level of investment, $b_{1}$. The home firm's period-1 revenue function is simply the negative of its investment cost function $C^{1}\left(a_{1}\right)$; while in period 2 investment lowers production costs $C^{2}\left(a_{1}, q_{2}\right)$ at a given level of output $q_{2}$ and so raises revenue: $R_{a 1}^{2}=-C_{a 1}^{2}>0 .{ }^{13}$ As a result, both $R_{b 1}^{1}$ and $R_{b 1}^{2}$ are zero, and so the terms in parentheses in (10) and (11) are zero. Furthermore, the foreign firm's firstorder conditions (7) do not depend directly on the home firm's level of investment in FCE, so the coefficient $B_{21}$ in (10) is also zero. ${ }^{14}$ The implications for the optimal subsidies are immediate: the period-2 subsidy reflects intratemporal profit-shifting solely, while in FCE there is no profit-shifting motive whatsoever in the expression for the period-1 subsidy. So, if firms do

12 Shapiro (1989, Section 4.4) gives a more comprehensive review of applications of two-period oligopoly games, though he does not discuss policy issues.

${ }_{13}$ Recall that $q_{2}$ is period-2 output, equal to $a_{2}$ in Cournot competition and $q_{2}\left(a_{2}, b_{2}\right)$ in Bertrand competition. This specification of costs allows for many interesting special cases, including that of marginal cost independent of output: $C^{2}\left(a_{1}, q_{2}\right)=c\left(a_{1}\right) q_{2}, c^{\prime}<0$; and the 'plant design' model of Vives (1989) which allows for a trade-off between fixed and variable costs: $C^{2}\left(a_{1}, q_{2}\right)=c\left(a_{1}\right) q_{2}+a_{1} q_{2}^{2}$, $c^{\prime}<0$.

14 The same is not true in GCE: since $a_{2}$ depends on $a_{1}$, so also does $d a_{2} / d b_{1}$. However, since this effect works only through changes in the curvature of the home firm's period-2 reaction function, it is unlikely to be very important. For example, it vanishes in the case of Cournot competition if marginal costs are independent of output. 
not invest strategically (i.e., in FCE), there is no justification for taxing or subsidising investment. And, whether they do or not, the optimal period-2 intervention has the same form as in models without investment.

The case where firms behave strategically and second-period competition is Cournot has been considered by Spencer and Brander (1983) and falls into the upper left-hand box of Table 1. Higher investment makes the home firm tough (i.e., it reduces the foreign firm's profits) and outputs are 'normally' strategic substitutes. Hence, the home firm has an incentive to over-invest relative to the social optimum and the optimal period-1 policy is an investment tax. Extending Fudenberg and Tirole's taxonomy, the government should restrain this 'top dog'. Of course, this need not mean that investment is lower overall, when the full effect of intervention is taken into account. Fig. 1 illustrates (under the simplifying assumption that the foreign firm does not invest). Without intervention, strategic behaviour by the home firm leads to

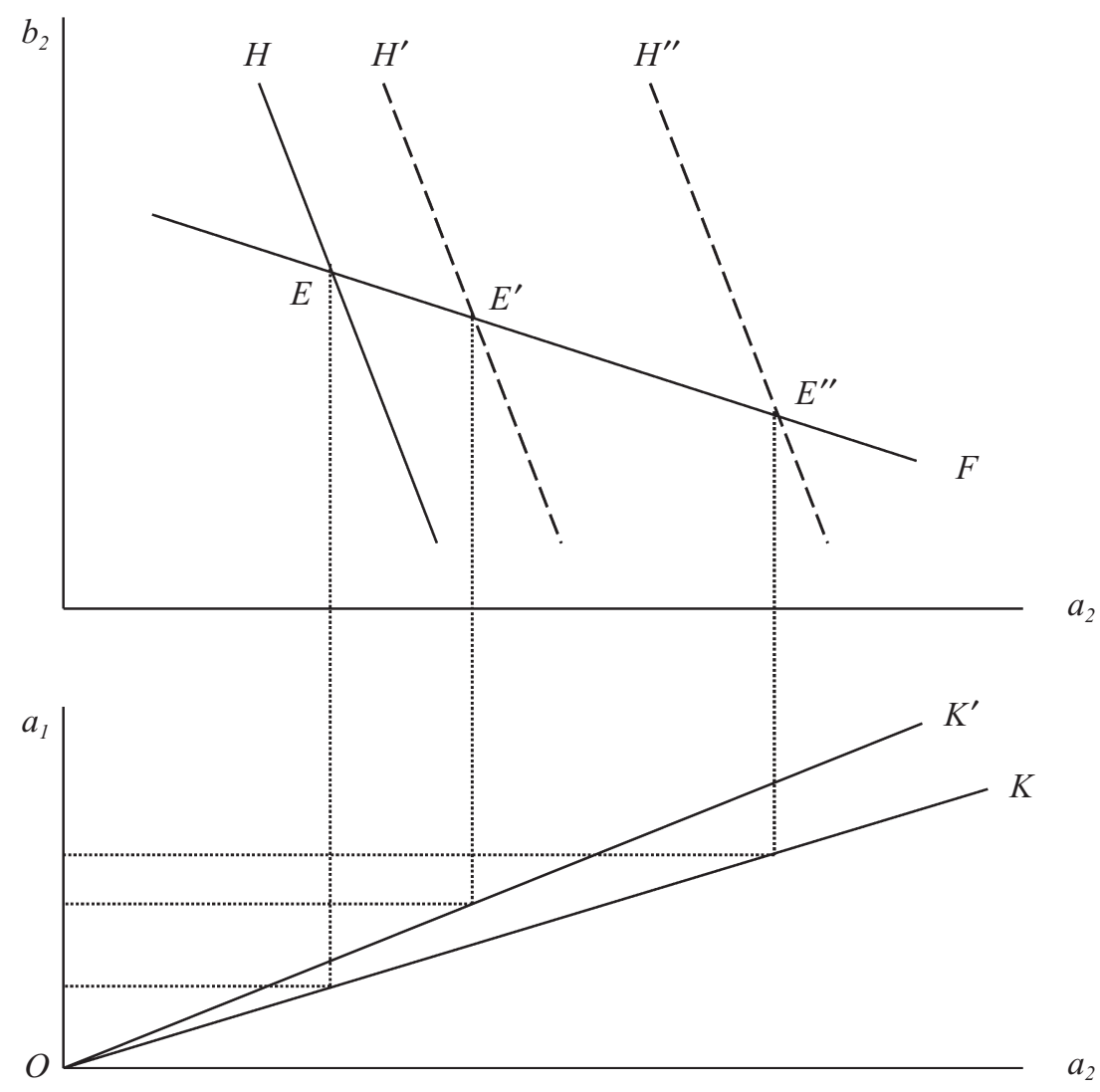

Fig. 1. Investment with Cournot Competition:

$a_{1}$ is investment, $a_{2}$ and $b_{2}$ are outputs. In free trade, strategic over-investment by the home firm shifts $O K$ to $O K^{\prime}$ and $H$ to $H^{\prime}$. Optimal intervention $\left(s_{1}<0, s_{2}>0\right)$ restores efficient investment but leads to still more output and investment at $E^{\prime \prime}$.

(C) Royal Economic Society 2000 
inefficient over-investment along $O K^{\prime}$ rather than the efficient locus $O K$, which shifts its output reaction function outwards from $H$ to $H^{\prime}$. The optimum GCE policy package of an investment tax and an export subsidy restores efficient investment, though (at least with linear demands) investment and output are still higher.

By contrast, if period-2 competition is in terms of prices, the second-period reaction functions are 'normally' upward-sloping. Investment still makes the home firm tough but now it has an incentive to under-invest, leading to higher prices for both firms. To counteract this behaviour, the optimal policy is an investment subsidy: this 'puppy dog' should be encouraged. In this case, the net effect on investment is ambiguous. Fig. 2 illustrates one possible outcome.

The considerations discussed so far apply only to the home firm's strategic behaviour against its foreign rival. In SE it also behaves strategically against the home government, to an extent determined by $d s_{2} / d a_{1}$. The Appendix shows that this term is presumptively positive when second-period competition is

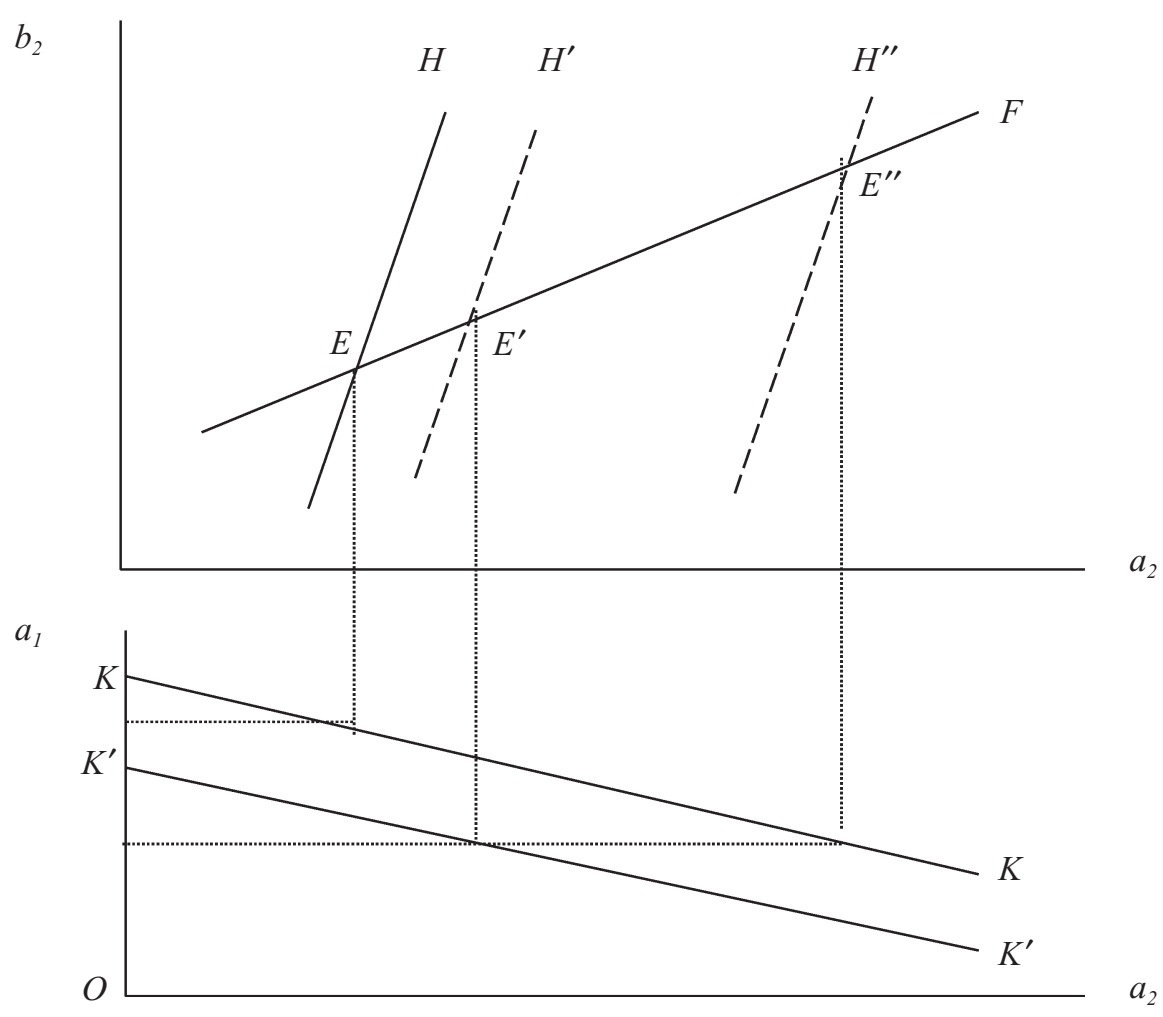

Fig. 2. Investment with Bertrand Competition:

$a_{1}$ is investment, $a_{2}$ and $b_{2}$ are prices. In free trade, strategic under-investment by the home firm shifts $K K$ to $K^{\prime} K^{\prime}$ and $H$ to $H^{\prime}$. Optimal intervention $\left(s_{1}>0, s_{2}<0\right)$ restores efficient investment and may (but need not) lead to still higher prices and lower investment at $E^{\prime \prime}$.

(C) Royal Economic Society 2000 
Cournot and negative when it is Bertrand.${ }^{15}$ Hence in Cournot competion the future subsidy is a strategic complement for the home firm's investment. As a result, the home firm has a further incentive to over-invest in order to obtain a higher subsidy, and so the government has a further motive to tax it in period 1 in order to restrain it from this socially wasteful behaviour. A similar chain of reasoning, but with opposite implications, applies in Bertrand competition. Higher investment in period 1 lowers costs and raises output in period 2, presumptively mandating a higher $\operatorname{tax}$ (i.e., a lower value of $s_{2}$ ). Thus the future subsidy is a strategic substitute for the home firm's investment, encouraging the home firm to under-invest and so justifying a subsidy in period 1 to restore the efficient level of investment.

\subsection{Learning by Doing}

Learning by doing is similar to investment in capacity or R\&D in the absence of policy (provided we continue to rule out inter-firm spillovers). However, when we consider its implications for policy, there are two important differences. First, since the firms compete directly in the first period, there is a profit-shifting motive for intervening in that period. Second, if competition in the first period is Bertrand, a firm which enjoys learning by doing faces different incentives from those in the investment case.

We have considered this case in Leahy and Neary $(1994,1999 b)$, drawing on Spence (1981) and Fudenberg and Tirole (1983), so our treatment can be brief. Because of learning by doing each firm's period-2 costs are inversely related to its period-1 output. Hence the second-period revenue function for the home firm becomes:

$$
R^{2}\left(a_{1}, b_{1}, a_{2}, b_{2}\right)=\hat{R}^{2}\left(a_{2}, b_{2}\right)-C^{2}\left(q_{1}, q_{2}\right),
$$

with $R_{a 1}^{2}$ positive if firms are Cournot competitors in the first period and negative if they are Bertrand competitors. Firms also compete directly in the first period, so the home firm's period- 1 revenue function is now $R^{1}\left(a_{1}, b_{1}\right)$. Hence, no terms vanish from (10) and (11) for the optimal subsidies. Even in FCE there is both an intertemporal and an intratemporal profit-shifting motive for intervention in both periods. These terms are more complex than in static models but there is a presumption that they have the same implications for policy, mandating subsidies in both periods when competition is Cournot (provided outputs are strategic substitutes) and taxes in both periods when competition is Bertrand (provided prices are strategic complements).

Consider next the inter-firm strategic effect. In Cournot competition this operates just as in the investment case. The home firm has an incentive to

\footnotetext{
15 Since higher investment (an increase in $a_{1}$ ) lowers costs in period 2, the sign of this second strategic effect hinges on whether a reduction in costs mandates a higher subsidy in period 2. The study of how changes in costs affect the optimal subsidy was initiated by de Meza (1986) and Neary (1994), and in Leahy and Neary $(1999 b)$ we derived a necessary and sufficient condition for this effect in Cournot competition. The Appendix provides a simpler proof which applies to Bertrand as well as Cournot competition.
}

(C) Royal Economic Society 2000 
over-produce in period 1 and the government should tax its output to restrain this 'top dog' behaviour. (Of course, the tax is relative to the profit-shifting benchmark, which is unambiguously positive if outputs are strategic substitutes.) However, in Bertrand competition the parallel with the investment case breaks down, although the policy implication is the same. 'Investment' now means a higher price in period 1 and, by lowering the rate of learning, this tends to raise the home firm's price in period 2 and so to increase the rival firm's profits. Hence, investment makes the home firm 'soft' and, provided prices are strategic complements, it has an incentive to under-invest. The optimal policy response is to exercise this 'fat cat' by reducing its current price, which requires an output subsidy, as shown in the lower right-hand cell in Table 1. Finally, the strategic effect vis-à-vis the government operates just as in the investment case, presumptively mandating a tax in the Cournot case but a subsidy in the Bertrand case.

\subsection{Natural Resources}

The approach we have taken so far can be applied to the problem of optimal policy towards a resource-exporting firm competing against a single foreign rival. The simplest case is where each firm has a fixed stock of the resource, so in Cournot competition $a_{1}+a_{2}=A$ and $b_{1}+b_{2}=B$. In this case, both intertemporal and strategic considerations vanish. The model effectively collapses to a one-period one and the only motive for intervention is intratemporal profit shifting. The home firm's first-order condition is simply $R_{a 1}^{1}+s_{1}=\rho\left(R_{a 2}^{2}+s_{2}\right)$, which implies a variant of the Hotelling rule: the subsidy-inclusive marginal profitability of resource extraction falls at the rate of time preference.

Of more interest is the case where a higher rate of extraction in period 1 raises the costs of extraction in period 2. ${ }^{16}$ This specification of technology is formally identical to learning by doing, except that the learning parameter is negative: future costs are increasing in current output. Hence higher output in period 1 makes the home firm 'soft' and so the case of Cournot competition falls into the upper-right-hand box of Table 1. Left to itself the home firm will under-produce in period 1, adopting a 'lean and hungry look'. Hence optimal intervention requires that it be fattened by a subsidy. Conversely, in Bertrand competition, a higher price in period 1 makes the home firm 'tough'. Assuming prices are strategic complements, this leads it to adopt a 'puppy dog' strategy in the sense that it under-prices; though the terminology is less appropriate here, since this implies that it over-produces and so the optimal policy (relative as always to the profit-shifting benchmark) is an output tax.

\footnotetext{
16 Optimal policy in this case has been considered by Maskin and Newbery (1990) in a different context: they assumed that the resource was produced by a competitive industry and compared the optimal tariff schedules for a resource-importing country with and without government commitment.

(C) Royal Economic Society 2000
} 


\subsection{REंD Spillovers}

In the examples considered so far, each firm's second-period costs depended only on its own first-period actions and not on its rival's. This simplicity vanishes if there are spillovers between firms, as in Spence (1984) and d'Aspremont and Jacquemin (1988). Moreover, the Fudenberg and Tirole taxonomy is no longer adequate, since from (13) there is an extra externality term in $d b_{2} / d a_{1}$. Some of the benefits of the home firm's $\mathrm{R} \& \mathrm{D}$ accrue to the foreign firm, reducing its costs and tending to raise its output. This indirect effect tends to make the home firm 'soft', working against the direct effect considered in Section 2.1.

To see which effect dominates, we must calculate explicitly the inter-firm strategic effect in the home firm's first-order condition (4). The home firm's revenue functions are now:

$$
R^{1}\left(a_{1}\right)=-C^{1}\left(a_{1}\right), R^{2}\left(a_{1}, b_{1}, a_{2}, b_{2}\right)=\hat{R}^{2}\left(a_{2}, b_{2}\right)-C^{2}\left(a_{1}, b_{1}, q_{2}\right),
$$

with corresponding expressions for the foreign firm. Differentiating the two firms' first-order conditions in period 2 gives:

$$
\begin{aligned}
& \pi_{b_{2}}^{2} \frac{d b_{2}}{d a_{1}}=A(\bar{\beta}-\beta), \\
& A \equiv \pi_{b_{2}}^{2} \frac{\pi_{a_{2} a_{2}}^{2} \pi_{b_{2} b_{1}}^{*}}{\Delta}>0, \bar{\beta} \equiv \frac{\pi_{b_{2} a_{2}}^{* 2}}{\pi_{a_{2} a_{2}}^{2}} \frac{\pi_{a_{2} a_{1}}^{2}}{\pi_{b_{2} b_{1}}^{* 2}} \quad \text { and } \beta \equiv \frac{\pi_{b_{2} a_{1}}^{* 2}}{\pi_{b_{2} b_{1}}^{* 2}}=\frac{C_{q_{2}^{*} a_{1}}^{* 2}}{C_{q_{2}^{*} b_{1}}^{* 2}}
\end{aligned}
$$

Second-order and stability conditions ensure that the term $A$ is always positive. ${ }^{17}$ Hence, the spillover effect dominates, and investment makes the home firm 'soft', if and only if $\beta$ is greater than $\bar{\beta}$. These two parameters are easily interpreted. $\beta$ equals the ratio of 'cross' to 'own' effects of $\mathrm{R} \& \mathrm{D}$ on the foreign firm's marginal costs. It is natural to interpret this as a measure of the strength of spillovers, and to require it to lie between zero (the case of Section 2.1 with no spillovers) and one (the case where $\mathrm{R} \& \mathrm{D}$ is completely unappropriable). This leaves $\bar{\beta}$ as the threshold value for $\beta$. The key feature of $\bar{\beta}$ is that (as in the symmetric closed-economy model of Leahy and Neary (1997)), it is positive if and only if $b_{2}$ is a strategic substitute for $a_{2}\left(\right.$ so that $\left.\pi_{b_{2} a_{2}}^{* 2}<0\right) .{ }^{18}$ In the special case of homogeneous-product Cournot competition, linear demands and a symmetric quadratic specification of $\mathrm{R} \& \mathrm{D}, \bar{\beta}$ equals one half, the value found by d'Aspremont and Jacquemin (1988).

17 The denominator $\Delta$, the determinant of the coefficient matrix, is positive from stability of the period-2 game; and the term $\pi_{a_{2} a_{2}}^{2}$ is negative from the home firm's second-order condition. As for the other two terms in $A$, they always differ in sign. If period-2 competition is Cournot, $\pi_{b_{1}}^{2}$ is negative (a rise in foreign output reduces home profits) and $\pi_{b_{2} b_{2}}^{* 2}$ is positive (a rise in foreign investment tends to raise foreign output). Both signs are reversed in Bertrand competition. The net effect is therefore that $A$ must be positive.

${ }_{18} \bar{\beta}$ is the product of two terms. The second of these must be positive, since it equals the ratio of 'own' effects of R\&D on period-2 marginal profitability for the two firms. The denominator of the first term must be negative from the home firm's period-2 second-order condition. Hence the sign of $\bar{\beta}$ depends solely on the sign of the numerator of the first term; i.e., on whether the foreign firm's period2 action is a strategic substitute or a strategic complement for the home firm's.

(C) Royal Economic Society 2000 
Summarising, the total strategic effect leads the home firm to overinvest in $\mathrm{R} \& \mathrm{D}$ and so justifies an R\&D tax for low spillovers $(\beta<\bar{\beta})$; whereas an $\mathrm{R} \& \mathrm{D}$ subsidy is justified for high spillovers $(\beta>\bar{\beta})$; and a subsidy is always justified when period-2 actions are strategic complements (since then $\beta>0>\bar{\beta}$ ). At first sight it may seem paradoxical that an R\&D subsidy is more likely, the greater the spillovers to the foreign firm, whose profits are of no concern to the home government. The source of the paradox lies in the strategic behaviour by the home firm, which leads it to under-invest in R\&D when spillovers are high. ${ }^{19}$

\subsection{Consumer Switching Costs}

The final application we consider is to the case of switching costs in demand, as studied by Klemperer (1995) and To (1994). The period-2 revenue function can now be written as:

$$
R^{2}\left(a_{1}, b_{1}, a_{2}, b_{2}\right)=\hat{R}^{2}\left[\alpha\left(a_{1}, b_{1}\right), a_{2}, b_{2}\right]
$$

where $\alpha$ denotes the home firm's market share in period 1, equal to $q_{1} /\left(q_{1}+q_{1}^{*}\right)$. While the rationale for this specification differs greatly from that for R\&D spillovers as considered in Section 2.4, they both imply the same form for the strategic effect. Thus (20) still holds in this case, the only difference being the form of the 'spillover' parameter $\beta$ :

$$
\beta \equiv \frac{\pi_{b_{2} a_{1}}^{* 2}}{\pi_{b_{2} b_{1}}^{* 2}}=\frac{\alpha_{a_{1}}^{*}}{\mathrm{a}_{b_{1}}^{*}} .
$$

$\beta$ is now the ratio of 'cross' to 'own' effects of period-1 actions on the foreign firm's period-1 market share, $\alpha^{*}$. But since $a_{1}$ and $b_{1}$ have opposite effects on market shares (irrespective of whether competition in period 1 is in quantities or prices), $\beta$ must be negative. (Though, as in Section 2.4, it is likely to be less than one in absolute value.) The implications for optimal policy are very similar to those in the previous sub-section. The only substantive difference is that the ambiguity in sign of the strategic component of the optimal subsidy now arises when actions are strategic complements, rather than when they are strategic substitutes. The threshold parameter $\bar{\beta}$ is still positive if and only if period-2 actions are strategic substitutes; in that case we can be sure that $\beta<\bar{\beta}$ and so the home firm 'over-acts' in period 1, justifying a tax. By contrast, if period-2 actions are strategic complements, then both $\beta$ and $\bar{\beta}$ are negative and the appropriate policy depends on their relative magnitudes.

\footnotetext{
19 Further implications of strategic behaviour for policy towards R\&D in the presence of both international and domestic spillovers are considered in Leahy and Neary (1999a).

(C) Royal Economic Society 2000
} 


\section{Optimal Second-Best Intervention}

All the applications considered in Section 2 have remained within the framework of Section 1. This makes a number of restrictive assumptions, such as a passive foreign government, no home consumption and only one home firm. However, relaxing these introduces considerations which are not peculiar to an intertemporal framework and which are familiar from earlier work..$^{20}$ In this section, we turn instead to a key dynamic assumption made so far: that the home government can subsidise in both periods. In reality, governments often face constraints on their freedom to intervene. For example, the WTO (formerly the GATT) prohibits explicit export subsidies but does not constrain investment subsidies. Alternatively, it may be possible to evade the WTO prohibition on export subsidies (e.g., by providing export credits) but budgetary constraints may preclude direct assistance to investment. To understand such situations, it is desirable to extend the analysis of previous sections to the case where the government can vary only one instrument. We call this 'secondbest' intervention in contrast to the 'first-best' intervention of previous sections. (Throughout the paper we are concerned with maximising national welfare only; maximising global welfare would require removing oligopolistic distortions.)

If only one instrument is available, it matters crucially whether or not the government can commit to it in advance of any decisions by firms. Consider first the case where the government has the ability to commit. We can then adapt the methods of Section 1 to derive the optimal second-best value of the sole available instrument. Write the formulae for the first-best optimal subsidies (given by the right-hand sides of (10) and (11)) as $\bar{S}_{1}$ and $\bar{S}_{2}$ respectively. Now we can immediately rewrite the change in welfare from (6) in terms of the deviations of the subsidy terms from their first-best values:

$$
d W=-\left(S_{a_{1}}-\bar{S}_{1}\right) d a_{1}-\left(S_{a_{2}}-\bar{S}_{2}\right) d a_{2} .
$$

If the period $j$ subsidy is unalterable, the optimal value of the period $i$ subsidy term is:

$$
S_{a_{i}}^{0}=\bar{S}_{i}-\left.\left(S_{a_{j}}-\bar{S}_{j}\right) \frac{d a_{j}}{d a_{i}}\right|_{s_{j}}, i, j=1,2 ; i \neq j .
$$

Thus the optimal second-best subsidy term in period $i$ equals the value given

${ }^{20}$ See Brander (1995) for an overview and extensive references. Allowing for an active foreign government does not alter the formulae for the optimal home subsidies (except in SE), so there is a presumption that their signs are unchanged. However, if governments play a Nash game in subsidies, the actual equilibrium will be very different from the unilateral optimum, typically with lower welfare for both countries when firms play Cournot but higher when they play Bertrand. (See Leahy and Neary $(1999 b)$.) Allowing for home consumption increases both the number of targets facing the government (consumption levels in addition to outputs) and the number of instruments potentially available to it (tariffs and production subsidies in addition to export subsidies). It may also change the model in other ways depending on whether the home and foreign markets are integrated or segmented. Finally, allowing for more than one domestic firm leads to pecuniary externalities between firms (unless they collude) which encourages export taxes for familiar terms of trade reasons. It also strengthens the case for subsidisation with R\&D spillovers, unless firms engage in cooperative research joint ventures.

(C) Royal Economic Society 2000 
by the first-best formula $\bar{S}_{i}$, less a correction factor which is the product of two terms: first, the deviation of the other subsidy term from its first-best value and, second, the extent to which, with $s_{j}$ unalterable, a change in $a_{i}$ affects $a_{j}$. The underlying rationale is similar to that in competitive models. (See for example, Neary (1995).) If the two home-firm actions $a_{i}$ and $a_{j}$ (which are the 'targets' from the home government's perspective) are complements in the sense that $d a_{j} / d a_{i}$ is positive, then the deviations of the two 'instruments' $S_{a i}$ and $S_{a j}$ from their respective first-best optimal values should be opposite in sign.

To illustrate this result more concretely, note that the two equations in (25) define second-best loci which can be illustrated in subsidy space. Figs 3 and 4 show the loci implied by the investment model of Section $2.1 .^{21}$ In each figure the first-best optimum is denoted by point $A$; the contours are iso-welfare loci; the blank regions at the extremities of the figures correspond to subsidy values that are either too high or too low to sustain an interior equilibrium; and units are chosen such that welfare equals unity in free trade (i.e., at the $s_{1}=s_{2}=0$ origin).

Consider first the case of investment followed by Cournot competition (Fig. 3). The two straight lines through $A$ are the two second-best optimal subsidy loci defined by (25). Both are downward-sloping, reflecting the fact that the government's two targets, home investment and home output, are

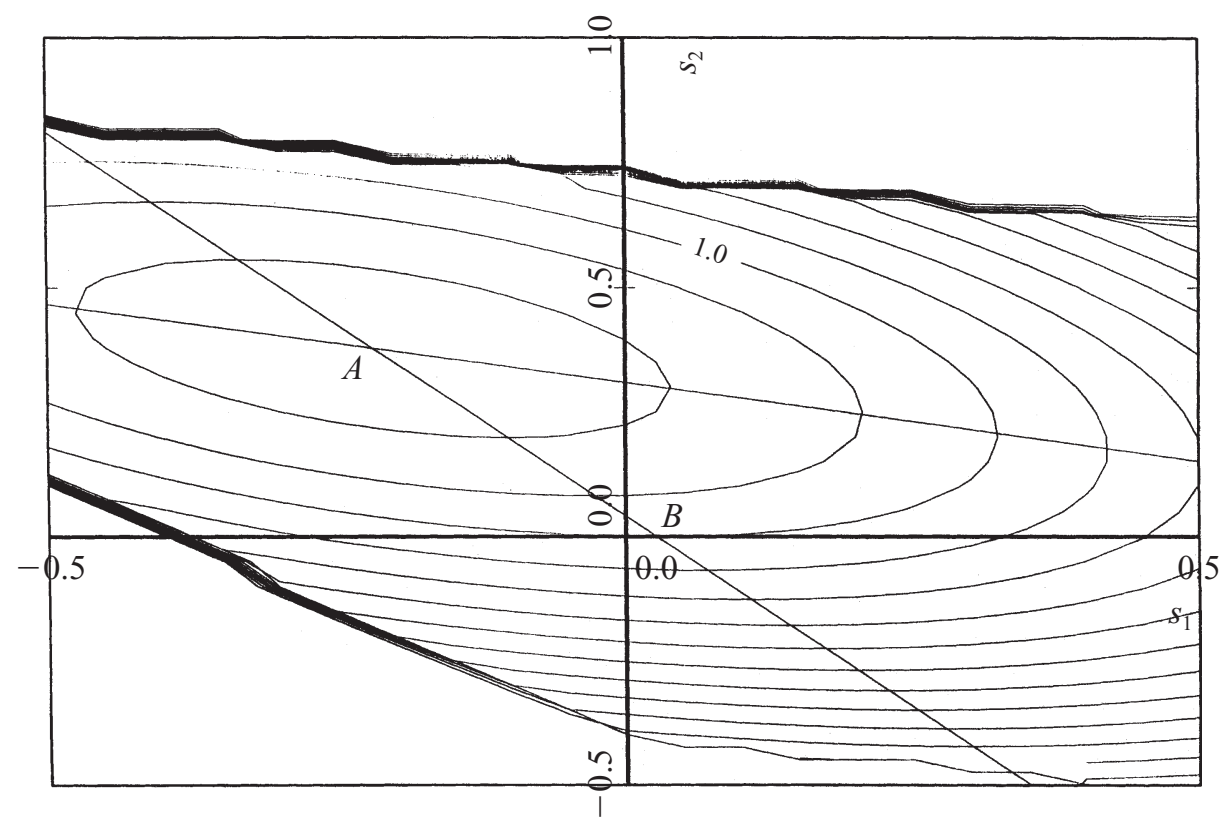

Fig. 3. Iso-Welfare Contours and Optimal Second-Best Subsidy Loci in RED-Cournot Game

21 The underlying calculations are given in detail in appendices to a longer version of this paper which, with the GAUSS program used to generate Figs 3 and 4, are available on request.

(C) Royal Economic Society 2000 


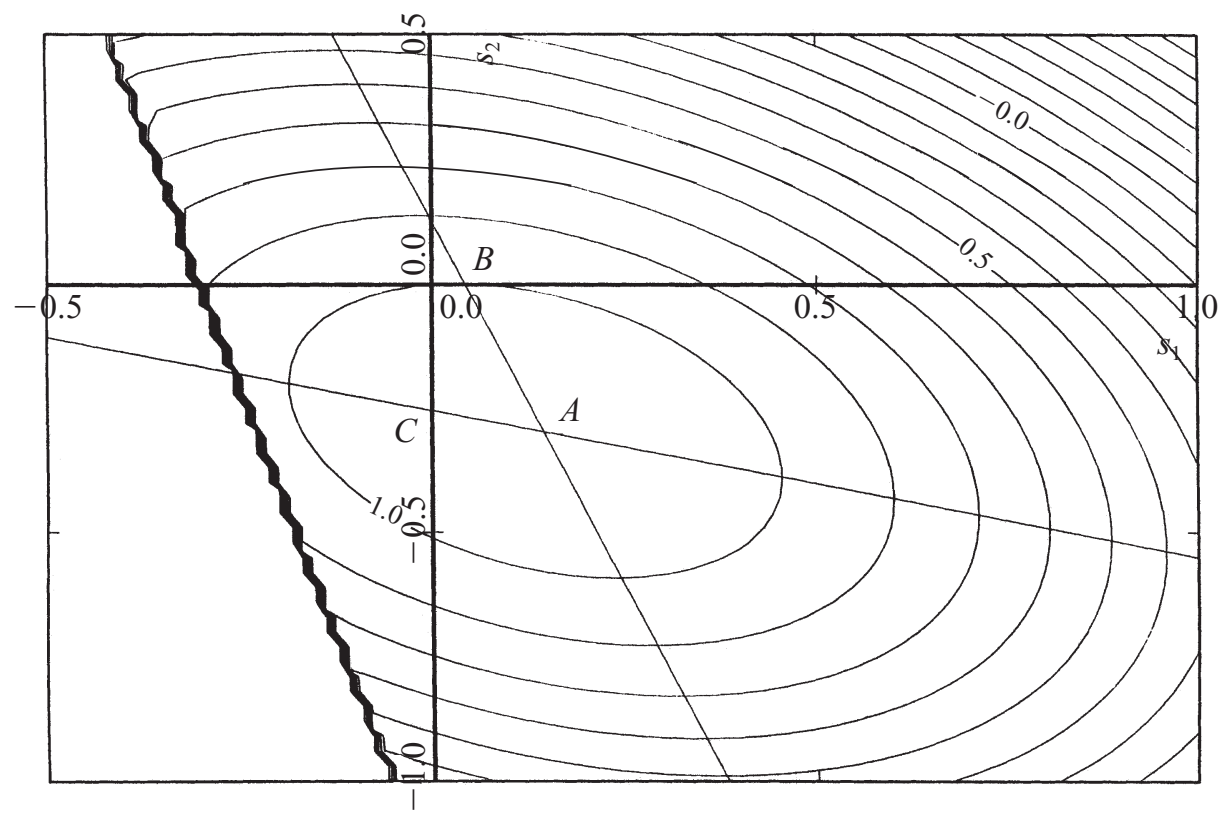

Fig. 4. Iso-Welfare Contours and Optimal Second-Best Subsidy Loci in REDD-Bertrand Game

indeed complements in this case. However, the loci never stray into the southwest quadrant, so both second-best subsidies are positive when the other subsidy is constrained to equal zero. Spencer and Brander (1983) demonstrated this for the investment subsidy, though Fig. 3 draws attention to a feature of their result which is inadequately appreciated. The motive for subsidising investment is only a second-best one, and is partly offset by the direct motive (the desire to counteract strategic over-investment) which works towards a tax. Hence the second-best investment subsidy is likely to be small in magnitude. This is true of the example illustrated in Fig. 3: the second-best subsidy at point $B$ is much lower in absolute value than the first-best tax at $A$ and, in addition, leads to only slightly higher welfare than free trade.

Fig. 4 shows the corresponding curves for the case of investment followed by Bertrand competition. As already noted in Section 2.1, the first-best package represented by point A exactly reverses that of the Cournot case in Fig. 3: now the optimum involves taxing exports but subsidising investment. However, the second-best loci through A are both downward-sloping, reflecting two mutually offsetting differences from the Cournot case. First, the two targets, home investment and the home firm's price, are now substitutes rather than complements. As a result, both subsidy formulae in (25) must lie on the same side of their respective first-best values. Offsetting this is the fact that, as always in Bertrand competition, $S_{a 2}$ is negatively related to the export subsidy, so the second-best optimal subsidy rates lie on opposite sides of their first-best values, just as in the Cournot case.

(C) Royal Economic Society 2000 
The other similarity between Figs 3 and 4 is that the optimal second-best investment subsidy is positive when the export subsidy is zero (at point $B$ ). This result was noted by Bagwell and Staiger (1994), whose findings were used by Brander (1995) as the basis for a conjecture that investment subsidies are a more robust recommendation (with respect to variations in assumptions about firm behaviour) than export subsidies. Fig. 4 provides further evidence for this conjecture, drawing on the results of Maggi (1996). He considers a model such as that of Fig. 4, with investment followed by price competition, concentrating on the sign of the optimal second-best export subsidy; i.e., on the location of point $C$. He focuses on the curvature of the marginal cost curve and shows that, if (as in the example illustrated in Fig. 4) it is horizontal, the optimal second-best export subsidy is negative. However, if the marginal cost curve is very steep, corresponding to a case where for a given level of investment the firm is constrained to produce at or near capacity output, then the optimal second-best output subsidy is positive. In terms of Fig. 4, point $C$ would then lie above the horizontal, and so point $B$ would lie even further to the right of the origin, strengthening the case for a positive second-best optimal investment subsidy. ${ }^{22}$

The final case is where the government is constrained to offer an export subsidy only but cannot commit to it in advance of firms' first-period actions. It is obvious that, in that case, the 'optimal' second-best policy will be given by the static formula (14). Of more interest is that welfare may now be lower with an export subsidy than it would be in free trade. (Of course, this comparison assumes that it is feasible for the government to commit to free trade, which in itself implies some degree of government commitment.) The circumstances in which such a second-best 'paradox' may arise have been considered by Karp and Perloff (1995), Grossman and Maggi (1998) and Neary and O’Sullivan (1999).

\section{Conclusion}

In this paper we have developed a general approach to the design of optimal trade and industrial policy towards dynamic oligopolies. We have identified three distinct motives for intervention. First is the standard profit-shifting one of using the government's superior powers of commitment to place the home firm in the position it would itself adopt if it had a Stackelberg first-mover advantage over the foreign firm. An added complication is that, when firms compete directly in more than one period, there is scope for inter- as well as intra-temporal profit-shifting. The second motive is the desire to counteract the strategic behaviour of the home firm vis-à-vis its rival. This type of strategic behaviour is summarised by Fudenberg and Tirole's 'animal spirits' taxonomy

22 The same point can be made by considering (25), with $i=2$ and $j=1$. In the model with investment followed by Bertrand competition, $\bar{S}_{1}=\bar{s}_{1}>0, \bar{S}_{2}=\bar{s}_{2} q_{a 2}>0$ (where $q_{a 2}$ is the own-price derivative of demand and is negative, so $\bar{s}_{2}$ is negative), and $S_{a 2}^{0}=s_{2}^{0} q_{a 2}$. If the marginal cost curve is very steep, $d a_{1} / d a_{2}$ (which is always negative) is very large in absolute value and so the second term in (25) dominates, implying that $s_{2}^{0}$ is positive.

(C) Royal Economic Society 2000 
of business strategies and the optimal subsidy should contain a term which exactly offsets it (implying an 'animal training' taxonomy of optimal policies). Finally, the third motive is the desire to counteract the home firm's strategic behaviour vis-à-vis the government's own future actions.

In summary, the government should exploit its own strategic power and should counteract the home firm's. This means using its powers of commitment both to shift profits (inter- as well as intratemporally) and to prevent the home firm from making socially wasteful commitments.

In addition to setting out the general principles which should guide intervention in a general dynamic oligopoly setting, we have examined their application in a number of special cases, including $\mathrm{R} \& \mathrm{D}$ (both with and without inter-firm spillovers), learning by doing, trade in natural resources and consumer switching costs. Our approach should prove fruitful in exploring issues of optimal intervention in the presence of many other types of intertemporal links. We have also shown how our general framework can be extended to allow for second-best policies. In all cases the properties of particular models can be explained in terms of a few simple general principles, and we have also noted some useful analogies between seemingly different problems. For example, we have shown that, except for a sign change, there is a formal identity between models with learning by doing and natural resources; and between models with $\mathrm{R} \& \mathrm{D}$ spillovers and consumer switching costs.

Finally, what do our results imply for the practice of intervention targeted towards oligopolistic firms in open economies? It should be obvious that the paper confirms the general thrust of the literature on strategic trade and industrial policy, that no simple rules of thumb to guide policy are available. Not just the magnitude but even the sign of optimal intervention depends on subtle and perhaps unobservable aspects of firm behaviour. More positively, and in line with the results of Maggi (1996), we find some tentative support for a conjecture of Brander (1995) that the case for investment subsidies is more robust than that for export subsidies. However, Sections 2.1 and 3 show that the implied policy recommendation (subsidise investment irrespective of the mode of competition) is at most a second-best one, in that it does not apply if exports as well as investment can be subsidised or taxed. Moreover, our simulations suggest that the potential gains from this limited form of intervention are likely to be small.

Yet the absence of any simple and universal rules for practical policy making does not detract from the intellectual significance of this branch of theory. In this respect, it may be helpful to draw an analogy between the theory of strategic trade policy and that great theoretical insight of the first decade of the twentieth century, Bickerdike's (1906) theory of optimal tariffs. For all sorts of practical reasons (of which the risk of foreign retaliation is the most obvious) the potential gains from manipulating the terms of trade are likely to be tiny, even for very large countries. Nevertheless, in trying to explain the welfare implications of actual interventions and the incentives facing governments in international negotiations, it is essential to understand the relation- 
ship between welfare and world prices and the potential if elusive gains from trying to exploit it. In exactly the same way, the potential role of a home government in taking on a Stackelberg leadership role which a home firm cannot take on for itself is a basic insight; even if there is little likelihood of realising the gains in practice. Given the enormous extent of intertemporal interdependence between firms, this suggests that the principles set out in this paper will remain central to future debates about the scope of public assistance to export-oriented firms.

\section{University College Dublin}

Date of receipt of first submission: December 1998

Date of receipt of final typescript: July 1999

\section{Appendix: Derivation of $d s_{2} / d a_{1}$}

To calculate $d s_{2} / d a_{1}$ in $\mathrm{SE}$, we need to solve jointly all three first-order conditions in period 2: one each for the home firm, the foreign firm and the government. We must also consider the government's problem in detail, since its second-order condition implies a useful restriction. We simplify by ignoring the dependence of $\pi^{* 2}$ and $S^{2}$ on $a_{1}$ : thus our results apply only to the cases of investment, learning by doing and natural resources of Sections 2.1 to 2.3. For convenience we suppress $b_{1}$ throughout, since we need consider only the home firm's behaviour.

Since the foreign firm is effectively passive in period 2, we may solve its first-order condition for its reaction function:

$$
b_{2}=\psi\left(a_{2}\right) .
$$

Taking this into account but treating $a_{1}$ as predetermined, the government's problem is to maximise period-2 welfare:

$$
\operatorname{Max}_{s_{2}} W^{2}=R^{2}\left[a_{1}, a_{2}, \psi\left(a_{2}\right)\right] .
$$

This leads to the first-order condition (which in turn leads to (14) in the text):

$$
\frac{d W^{2}}{d s_{2}}=\left\{R_{a_{2}}^{2}\left[a_{1}, a_{2}, \psi\left(a_{2}\right)\right]+R_{b_{2}}^{2}\left[a_{1}, a_{2}, \psi\left(a_{2}\right)\right] \cdot \psi_{a_{2}}\left(a_{2}\right)\right\} \frac{d a_{2}}{d s_{2}} .
$$

Totally differentiating (28) and evaluating at the optimum gives the second-order condition for the government's maximisation problem:

$$
\left.\frac{d^{2} W^{2}}{d s_{2}^{2}}\right|_{s_{2}=s_{2}^{s}}=\left[R_{a_{2} a_{2}}^{2}+R_{a_{2} b_{2}}^{2} \psi_{a_{2}}+\left(R_{b_{2} a_{2}}^{2}+R_{b_{2} b_{2}}^{2} \psi_{a_{2}}\right) \psi_{a_{2}}+R_{b_{2}}^{2} \psi_{a_{2} a_{2}}\right]\left(\frac{d a_{2}}{d s_{2}}\right)^{2} .
$$

Hence, irrespective of the sign of $d a_{2} / d s_{2}$, the second-order condition implies that the term in square brackets must be negative. Call this term $E$.

Now, totally differentiate the government's first-order condition from (28):

$$
d a_{2}=-E^{-1}\left(R_{a_{2} a_{1}}^{2}+R_{b_{2} a_{1}}^{2} \psi_{a_{2}}\right) d a_{1} .
$$

Finally, totally differentiate the home firm's first-order condition $\pi_{a 2}^{2}=0$ to obtain:

$$
\left(\pi_{a_{2} a_{2}}^{2}+\pi_{a_{2} b_{2}}^{2} \psi_{a_{2}}\right) d a_{2}+R_{a_{2} a_{1}}^{2} d a_{1}+S_{a_{2} s_{2}}^{2} d s_{2}=0,
$$

and use (30) to eliminate $d a_{2}$ :

(C) Royal Economic Society 2000 


$$
\begin{aligned}
(-E) S_{a_{2} s_{2}}^{2} \frac{d s_{2}}{d a_{1}}= & {\left[\left(R_{b_{2} a_{2}}^{2}+R_{b_{2} b_{2}}^{2} \psi_{a_{2}}\right) \psi_{a_{2}}+R_{b_{2}}^{2} \psi_{a_{2} a_{2}}-\left(S_{a_{2} a_{2}}^{2}+S_{a_{2} b_{2}}^{2} \psi_{a_{2}}\right)\right] R_{a_{2} a_{1}}^{2} } \\
& -\left(\pi_{a_{2} a_{2}}^{2}+\pi_{a_{2} b_{2}}^{2} \psi_{a_{2}}\right) \psi_{a_{2}} R_{b_{2} a_{1}}^{2} .
\end{aligned}
$$

This is the required expression for $d s_{2} / d a_{1}$. The only general restrictions which apply are that $E$ is negative from the government's second-order condition, as already noted, and that the final bracketed expression on the right-hand side, $\pi_{a_{2} a_{2}}^{2}+\pi_{a_{2} b_{2}}^{2} \psi_{a_{2}}$, is negative from the stability of the period-2 game. We therefore turn to consider some special cases.

In Cournot competition a number of terms simplify: $R_{a_{2} s_{2}}^{2}=1, S_{a_{2} a_{1}}^{2}=-C_{a_{1}}^{2}>0$ and $S_{a_{2} a_{2}}^{2}=S_{a_{2} b_{2}}^{2}=R_{b_{2} a_{1}}^{2}=0$. If in addition we assume that products are homogeneous, standard properties of the revenue function are that $R_{b_{2} a_{2}}^{2}=p_{2}^{\prime}\left(1+\alpha_{2} r_{2}\right)$ and $R_{b_{2} b_{2}}^{2}=p_{2}^{\prime} \alpha_{2} r_{2}$, where $\alpha_{2}$ is the market share of the home firm, $p_{2}^{\prime}$ is the slope and $r_{2}$ $\left(=\left(a_{2}+b_{2}\right) p_{2}^{\prime \prime} / p_{2}^{\prime}\right)$ is the degree of concavity of the demand function. Hence (32) simplifies to:

$$
(-E) \frac{d s_{2}}{d a_{1}}=p_{2}^{\prime} \psi_{a_{2}}\left[1+\alpha_{2} r_{2}\left(1+\psi_{a_{2}}\right)+a_{2} \psi_{a_{2} a_{2}} / \psi_{a_{2}}\right]\left(-C_{a_{1}}^{2}\right) .
$$

Since $p_{2}^{\prime}, \psi_{a_{2}}$ and $C_{a_{1}}^{2}$ are all negative, $d s_{2} / d a_{1}$ is positive if and only if the expression in square brackets is positive, confirming Proposition 3 in Leahy and Neary (1999b). With linear demands, $r_{2}=\psi_{a_{2} a_{2}}=0$, and the expression reduces to unity. More generally, there is still a presumption that it is positive provided neither the demand function not the foreign reaction function is 'too' convex.

In Bertrand competition, no terms disappear but we have a number of restrictions: $\psi_{a_{2}}>0$, assuming prices are strategic complements; $S_{a_{2} s_{2}}^{2}=q_{a_{2}}^{2}<0, \quad R_{a_{2} a_{1}}^{2}=$ $-C_{a_{1}}^{2} q_{a_{2}}^{2}<0$ and $R_{b_{2} a_{1}}^{2}=-C_{a_{1}}^{2} q_{a_{2}}^{2}<0$ (recalling that $a_{2}$ and $b_{2}$ are home and foreign prices respectively). With linear demands, (32) reduces to:

$$
(-E) \frac{d s_{2}}{d a_{1}}=-q_{b_{2}}^{2} \psi_{a_{2}}\left(1+\frac{q_{b_{2}}^{2}}{q_{a_{2}}^{2}} \psi_{a_{2}}\right)\left(-C_{a_{1}}^{2}\right),
$$

where the slope of the foreign reaction function is: $\psi_{a_{2}}=-q_{a_{2}}^{* 2} / 2 q_{b_{2}}^{* 2}>0$. Assuming that own-price effects dominate cross-price effects, the right-hand side of (34) must be negative and so higher investment reduces the period-2 subsidy (or, rather, increases the period-2 tax). This continues to be the general presumption, as long as the second derivatives of the demand and foreign reaction functions do not dominate.

\section{References}

Bagwell, K. and Staiger, R. W. (1994). 'The sensitivity of strategic and corrective R\&D policy in oligopolistic industries.' Journal of International Economics, vol. 36, pp. 133-50.

Bickerdike, C. F. (1906). 'The theory of incipient taxes.' ECONOMIC JournaL, vol. 16, pp. 529-35.

Brander, J. A. (1995). 'Strategic trade policy.' In Handbook of International Economics, Vol. III (G. Grossman and K. Rogoff, eds), pp. 1395-455. Amsterdam: North-Holland.

Brander, J. A. and Spencer, B. J. (1985). 'Export subsidies and international market share rivalry.' Journal of International Economics, vol. 18, pp. 83-100.

Brander, J. A. and Spencer, B. J. (1987). 'Foreign direct investment with unemployment and endogenous taxes and tariffs.' Journal of International Economics, vol. 22, pp. 257-79.

Carmichael, C. M. (1987). 'The control of export credit subsidies and its welfare consequences.' Journal of International Economics, vol. 23, pp. 1-19.

d'Aspremont, C. and Jacquemin, A. (1988). 'Cooperative and noncooperative R\&D in duopoly with spillovers.' American Economic Review, vol. 78, pp. 1133-7.

de Meza, D. (1986). 'Export subsidies and high productivity: cause or effect?' Canadian Journal of Economics, vol. 19, pp. 347-50.

(C) Royal Economic Society 2000 
Dixit, A. (1980). 'The role of investment in entry deterrence.' ECONOMIC JournaL, vol. 90, pp. 95-106.

Eaton, J. and Grossman, G. M. (1986). 'Optimal trade and industrial policy under oligopoly.' Quarterly Journal of Economics, vol. 101, pp. 383-406.

Fudenberg, D. and Tirole, J. (1983). 'Learning by doing and market performance.' Bell Journal of Economics, vol. 14, pp. 522-30.

Fudenberg, D. and Tirole, J. (1984). 'The fat-cat effect, the puppy-dog ploy, and the lean and hungry look.' American Economic Review, vol. 74, (May), pp. 361-6.

Goldberg, P. K. (1995). 'Strategic export promotion in the absence of government precommitment.' International Economic Review, vol. 36, pp. 407-26.

Grossman, G. M. and Maggi, G. (1998). 'Free trade vs. strategic trade: a peek into Pandora's Box.' In (R. Sato, R. V. Ramachandran and K. Mino, eds) Global Competition and Integration, pp. 9-32. Dordrecht: Kluwer Academic Publishers.

Gruenspecht, H. K. (1988). 'Export subsidies for differentiated products.' Journal of International Economics, vol. 24, pp. 331-44.

Karp, L. S. and Perloff, J.M. (1995). 'The failure of strategic industrial policies due to manipulation by firms.' International Review of Economics and Finance, vol. 4, pp. 1-16.

Klemperer, P. (1995). 'Competition when consumers have switching costs: an overview with applications to industrial organization, macroeconomics, and international trade.' Review of Economic Studies, vol. 62, pp. 515-39.

Laussel, D. and Montet, C. (1994). 'Strategic trade policies.' In (D. Greenaway and L. A. Winters, ed.) Surveys in International Trade, pp. 177-205. Oxford: Basil Blackwell.

Leahy, D. and Neary, J. P. (1994). 'Time consistency, learning by doing and infant-industry protection: the linear case.' Economic and Social Review, vol. 26, pp. 59-68.

Leahy, D. and Neary, J. P. (1996). 'International R\&D rivalry and industrial strategy without government commitment.' Review of International Economics, vol. 4, pp. 322-38.

Leahy, D. and Neary, J. P. (1997). 'Public policy towards R\&D in oligopolistic industries.' American Economic Review, vol. 87, pp. 642-62.

Leahy, D. and Neary, J. P. (1999a). 'R\&D spillovers and the case for industrial policy in an open economy.' Oxford Economic Papers, vol. 51, pp. 40-59.

Leahy, D. and Neary, J. P. (1999b). 'Learning by doing, precommitment and infant-industry promotion.' Review of Economic Studies, vol. 66, pp. 447-74.

Maggi, G. (1996). 'Strategic trade policies with endogenous mode of competition.' American Economic Review, vol. 86, pp. 237-58.

Maskin, E. and Newbery, D. (1990). 'Disadvantageous oil tariffs and dynamic consistency.' American Economic Review, vol. 80, pp. 143-56.

Neary, J. P. (1991). 'Export subsidies and price competition.' In (E. Helpman and A. Razin, ed.) International Trade and Trade Policy, pp. 80-95. Cambridge, Mass.: MIT Press.

Neary, J. P. (1994). 'Cost asymmetries in international subsidy games: should governments help winners or losers?' Journal of International Economics, vol. 37, pp. 197-218.

Neary, J. P. (1995). 'Trade liberalisation and shadow prices in the presence of tariffs and quotas.' International Economic Review, vol. 36, pp. 531-54.

Neary, J. P. and O'Sullivan, P. (1999). 'Beat 'em or join 'em?: export subsidies versus international research joint ventures in oligopolistic markets.' Scandinavian Journal of Economics, vol. 101, pp. 577-96.

Shapiro, C. (1989). 'Theories of oligopoly behavior.' In (R. Schmalensee and R. Willig, eds) Handbook of Industrial Organization, Vol. 1, pp. 329-414. Amsterdam: North-Holland.

Spence, M. (1977). 'Entry, capacity, investment and oligopolistic pricing.' Bell Journal of Economics, vol. 8, pp. 534-44.

Spence, M. (1981). 'The learning curve and competition.' Bell Journal of Economics, vol. 12, pp. 49-70.

Spence, M. (1984). 'Cost reduction, competition and industry performance.' Econometrica, vol. 52, pp. 101-21.

Spencer, B. J. and Brander, J. A. (1983). 'International R\&D rivalry and industrial strategy.' Review of Economic Studies, vol. 50, pp. 707-22.

To, T. (1994). 'Export subsidies and oligopoly with switching costs.' Journal of International Economics, vol. 37, pp. 97-110.

Vives, X. (1989). 'Technological competition, uncertainty, and oligopoly.' Journal of Economic Theory, vol. 48, pp. 386-415. 